Keywords: Burnout, Caregiving, Dementia,

Alzheimer's disease, Burden of care, Brazil.

\title{
Burnout in a sample of Alzheimer's disease caregivers in Brazil
}

\author{
Annibal Truzzi ${ }^{\star}$ \\ Wanderson Souza** \\ Erika Bucasio** \\ William Berger** \\ Ivan Figueira ${ }^{\star *}$ \\ Eliasz Engelhardt* \\ Jerson Laks* \\ * Center for Alzheimer's disease and \\ Related Disorders, Institute of Psychiatry, \\ Federal University of Rio de Janeiro \\ ** Institute of Psychiatry, Federal University \\ of Rio de Janeiro
}

BRAZIL

\begin{abstract}
Background and Objectives: Caregiver burden has been associated to both caregiver and patient factors, but little is known about their relationship to burnout. We aimed at investigating burnout correlations to the sociodemographic and clinical variables of a sample of caregivers of Alzheimer's disease (AD) outpatients.

Methods: AD patients $(\mathrm{n}=69)$ and their caregivers completed a sociodemographic questionnaire, Maslach Burnout Inventory, Beck Depression and Anxiety Inventories. Patients were administered the Mini Mental State Examination, the Neuropsychiatric Inventory, Clinical Dementia Rating and the Functional Activities Questionnaire. Burnout and each dimension (emotional exhaustion, depersonalization, and reduced personal accomplishment) were correlated to caregivers' sociodemographic characteristics, burden of care, anxious and depressive symptoms as well as to the patients' behavioral, functional and cognitive profile.

Results: Burden of care was the only variable that associated to caregiver burnout. Emotional exhaustion was the most prevalent dimension and associated to all caregivers' and patients' clinical variables.

Conclusions: Caregiver burden associated to burnout, and emotional exhaustion is the dimension mostly associated to dementia severity and psychiatric morbidity in caregivers.
\end{abstract}




\section{Introduction}

Caregiving of dependent aged individuals is a major public health issue worldwide. Since the eighties the elderly population in developing countries is growing fast, with approximately 14.5 million subjects aged 65 years or more living in Brazil nowadays. Consequently, the Brazilian society is facing the burden of chronic and degenerative disorders including Alzheimer's disease (AD) which prevalence rate has been estimated as $7.1 \%^{1,2}$.

Burden of care in dementia represents a chief source of chronic stress to caregivers $^{3,4}$. A recent Brazilian study on the issue found high levels of psychological distress, exhaustion stress, anxiety, depression, and hopelessness in dementia caregivers although the dementia subtype of the patients was not assessed ${ }^{5}$.

The combination of chronic stress and loss of social contacts leads to an increase in caregiver risk of mental and physical diseases. Depression and anxiety are frequently seen in AD caregivers, with a depression prevalence ranging from $30 \%$ to $55 \%^{6,7}$. Furthermore, the chronic stress involved in constantly strenuous tasks make caregivers especially vulnerable to burnout.

Burnout is a psychological syndrome in response to chronic interpersonal stressors at the work environment. Burnout is usually viewed as having three dimensions, namely emotional exhaustion, depersonalization or cynicism, and reduced personal accomplishment. Emotional exhaustion is the feeling of being overextended and being depleted of one's resources. Depersonalization represents a detached response towards work, whereas reduced personal accomplishment refers to feelings of incompe- tence and lack of achievement at work. It is worth mentioning that burnout research began in caregiving and human services occupations in which work involved the presence of a care recipient and a provider ${ }^{8}$.

There is little information correlating burnout to the burden of care, the anxious and depressive symptoms, as well as to the cognitive, functional, and neuropsychiatric status of AD patients. The purpose of this study is to correlate burnout, including each dimension individually, to the sociodemographic and clinical characteristics of AD patients and their caregivers.

\section{Methods}

\section{Sample}

A convenience outpatient sample of 69 caregiver and $\mathrm{AD}$ patient dyads were consecutively included in this cross-sectional study. Patients were diagnosed as possible or probable Alzheimer's disease according to the National Institute of Neurological and Communicative Disorders and Stroke Alzheimer's Disease and Related Disorders Association $^{9}$ and the Diagnostic and Statistical Manual of Mental Disorders - Fourth Edition ${ }^{10}$ criterias. Caregivers were older than 18-years-old and both formal and informal caregivers were accepted. Informal caregiver is defined as the one who provides care without pay and whose relationship to the care recipient is due to personal ties, whereas formal caregiver refers to a professional, paraprofessional, or volunteer associated with a service system who provides care at home, in community agencies, institutions, or residential facilities $^{11,12}$. 


\section{Instruments}

Clinical, functional, and behavioral data of $\mathrm{AD}$ patients were assessed using the following instruments.

\section{Clinical Dementia Rating (CDR)}

CDR ranges from 0 for healthy people, 0.5 for questionable dementia and 1,2 and 3 for mild, moderate and severe dementia as defined in the scale. The total rating is made from the sum of boxes which represents an aggregate score of each individual's area ${ }^{13}$. We employed the validated Brazilian Portuguese version of the $\mathrm{CDR}^{14}$.

\section{Functional Activities Questionnaire (FAQ)}

The FAQ is a 10 -item scale that assesses instrumental and basic functional capacities in older people, each rated on a four-point scale ( 0 being normal and 3 incapable) and the maximum score is 30 points (severely disabled) ${ }^{15}$. The FAQ has been recommended as an useful instrument to assess functional abilities in the elderly Brazilian population ${ }^{16}$.

\section{Mini Mental State Examination (MMSE)}

The MMSE is probably the most widely used measure of cognitive function. The MMSE has a maximum score of 30 points, with different domains assessed: orientation to time and place (10 points), registration of 3 words ( 3 points), attention and calculation (5 points), recall of 3 words ( 3 points) and language $(8 \text { points })^{17}$. The MMSE version used in the study has been translated and validated to Brazilian portuguese ${ }^{18}$.

\section{Neuropsychiatric Inventory -10 (NPI)}

The NPI is a brief interview assessing 10 behavioral disturbances: delusions, hallucinations, dysphoria, anxiety, agitation/ aggression, euphoria, disinhibition, irritability/lability, apathy and aberrant motor behavior. Severity and frequency are independently assessed. It is scored from 1 to $120^{19}$. Recently, the Brazilian Portuguese version of the NPI was proved to be a reliable instrument for the evaluation of neuropsychiatric symptoms in AD Brazilian patients ${ }^{20}$.

The socio-demographic and clinical status of caregivers were assessed by means of the tests described below.

\section{Sociodemographic Questionnaire}

A brief self-administered sociodemographic questionnaire was developed by the authors in order to collect general sociodemographic data (age, gender, marital status, family relationship, scholarship and time as caregiver) from the caregivers.

\section{Beck Depression Inventory (BDI)}

The BDI is a 21-item self-rating scale that covers a variety of depressive symptoms including feelings of sadness, concerns about the future, suicidal ideation, tearfulness, sleep, fatigue, interests, worries about health, sexual interest, appetite, weight loss and general enjoyment. Each item is rated $0,1,2$ and 3 denoting increasing severity of symptoms ${ }^{21}$. The Brazilian version of the BDI validated by Gorestein and Andrade ${ }^{22}$ were employed.

\section{Beck Anxiety Inventory (BAI)}

It consists on a self-administered instrument with 21 items that covers the most frequently anxiety symptoms seen in clinical practice. Each item is scored 0, 1, 2 and 3 denoting increasing severity of symptoms ${ }^{23}$. The Brazilian Portuguese validated version of the BAI was administered ${ }^{24}$.

\section{Maslach Burnout Inventory (MBI)}

The MBI consists of a 22-item self-rating scale concerning the 3 dimensions of burnout: 
emotional exhaustion (9 items), depersonalization (5 items) and personal accomplishment (8 items). Frequency on each item is scored from 0 (never) to 6 (every day) ${ }^{25}$. Burnout is defined as the presence of high scores in both emotional exhaustion and depersonalization subscales, and low score in the personal accomplishment subscale. A cutoff score of 26 or more indicates the presence of high emotional exhaustion, 9 or more of high depersonalization and 33 or less of diminished personal accomplishment. The Brazilian Portuguese version of MBI, as well as the cut-off scores, adapted by a previous study performed in Brazil were employed ${ }^{26}$. Recently the MBI was proved useful in studies with caregivers of old people with dementia ${ }^{27}$.

\section{Burden Interview (BI)}

This is an interview developed for the assessment of burden of caregivers in caring for individuals with dementia. It is a 22item instrument rated by self-report and scored according to frequency ${ }^{28}$. The Brazilian version validated by Taub et al. ${ }^{29}$ was administered.

Approval for the study was granted by the Ethics Committee of the Federal University of Rio de Janeiro and all the participants signed the informed consent forms prior to any procedure.

\section{Statistical Analysis}

Results were expressed as means and standard deviation (SD). Mann-Whitney analyses were performed to compare both patients and caregiver's socio-demographic, cognitive, functional, and clinical characteristics according to the presence or not of burnout and its dimensions. Spearman's rank correlation was used to assess the relationship of burden and burnout with the variables mentioned above. Differences were considered statistically significant at $p \leq 0.05$. SPSS version 10 was used for data entry and analysis.

\section{Results}

The majority of caregivers were middleaged married daughters, who had at least elementary scholarship and a mean time as caregivers of $3.5(\mathrm{SD}=2.7)$ years. The mean NPI caregiver's distress was 7.5 ( $\mathrm{SD}=7.9$ ). Most patients exhibited a CDR $2(\mathrm{n}=29$; $42 \%$ ), which corresponds to a moderate level of the dementia. The socio-demographic characteristics of caregivers and the clinical profile of both caregivers and patients are summarized in Tables I and II.

Burnout was experienced by $6 \%(n=4)$ out of the 67 caregivers who agreed to answer the MBI. Emotional exhaustion was the most prevalent dimension $(\mathrm{n}=32$; $47.8 \%)$, followed by depersonalization $(\mathrm{n}=$ $19 ; 28.4 \%)$, and reduced personal accomplishment $(\mathrm{n}=19 ; 28.4 \%)$.

Burden of care was the only variable that independently associated to the presence of burnout in caregivers $(p<0.02)$. Patients' and caregivers' clinical data and their relations to burnout are described Table II.

Among all burnout dimensions, emotional exhaustion was highly associated to all clinical variables $(p<0.05)$. Caregivers who experienced emotional exhaustion also exhibited higher levels of depersonalization and reduced personal accomplishment $(p<0.05)$. The presence of depersonalization was associated significantly to higher scores on the NPI, the $\mathrm{BI}$ and the emotional exhaustion dimension $(p<0.05)$. Patients' and caregivers' clinical data and their associations to burnout dimensions are summarized in Table III. 
Table I

Caregivers' sociodemographic data

$\%(\mathrm{~N})$

Caregiver Gender

Male

$14.5(10)$

Female

$85.5(59)$

Caregiver Marital Status

Married

$49.3(34)$

Single

$26.1(18)$

Divorced

$20.3(14)$

Widow

$04.3(04)$

Level of Education

Elementary School $\quad 40.6(28)$

High School $\quad 29.0$ (20)

$\begin{array}{ll}\text { College } & 30.4(21)\end{array}$

Relationship

Children $43.5(30)$

Spouse 27.5 (19)

Distant relative/formal caregiver $\quad 23.2(16)$

$\begin{array}{ll}\text { Siblings } & 05.8(04)\end{array}$

Table II

Patients' and caregivers' characteristics in relation to caregiver burnout

\begin{tabular}{lcccc} 
& \multicolumn{2}{c}{ Burnout $^{2}$} \\
& Total $(\mathrm{N}=69)^{1}$ & Yes $(\mathrm{N}=4)$ & No $(\mathrm{N}=63)$ & p-value \\
\hline Patients & & & & \\
MMSE & $12.5(6.5)$ & $14(7.5)$ & $12.4(6.4)$ & 0.62 \\
NPI & $20.5(17.2)$ & $34.5(25.9)$ & $19.9(16.4)$ & 0.19 \\
FAQ & $22.4(8.2)$ & $20.5(8,4)$ & $22.4(8.2)$ & 0.71 \\
Caregivers & & & \\
Age (years) & $56.9(13.8)$ & $54.3(17.4)$ & $57.1(13.9)$ & 0.53 \\
Time as Caregiver (years) & $3.5(2.7)$ & $2.5(0.6)$ & $3.6(2.8)$ & 0.4 \\
BI & $35(16)$ & $48.5(7.8)$ & $34(15.9)$ & 0.02 \\
BAI & $6.5(7.9)$ & $7.8(7.5)$ & $6.4(8.1)$ & 0.56 \\
BDI & $9(7.8)$ & $13(8)$ & $8.4(7.3)$ & 0.18 \\
\hline
\end{tabular}

$* p<0.01$

${ }^{1}$ Mean (Standard Deviation)

MMSE = Mini Mental State Examination

2 Two participants refused to answer MBI

NPI $=$ Neuropsychiatric Inventory

$\mathrm{FAQ}=$ Functional Activities Questionnaire

$\mathrm{BI}=$ Burden Interview

$\mathrm{BAI}=$ Beck Anxiety Inventory

$\mathrm{BDI}=$ Beck Depression Inventory 


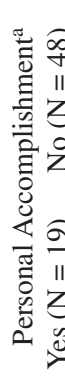

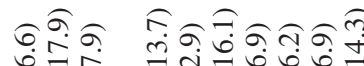

bon ann a

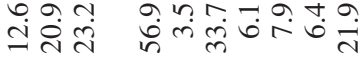

过

Єิำ

+ 00

⿺辶万๐

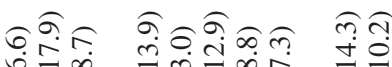

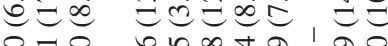
तबत

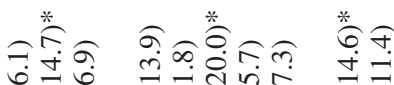

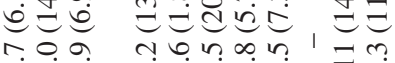

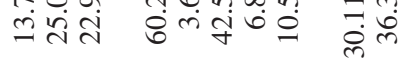

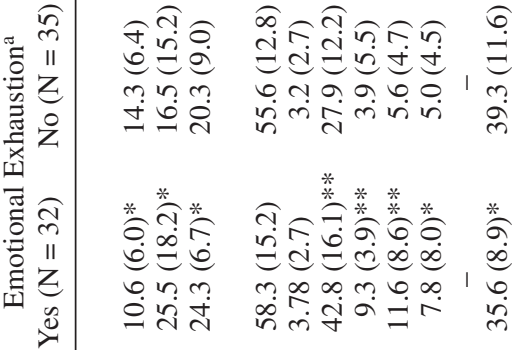

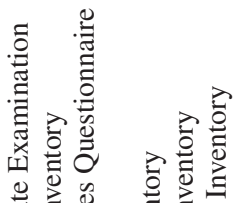

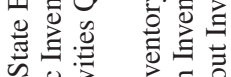

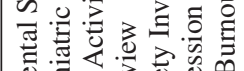

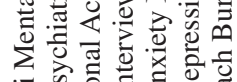

定. II 떼에

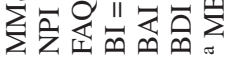

กิกิส ย包

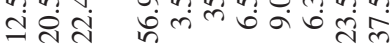


Correlations among burnout dimensions and other variables showed that emotional exhaustion was highly associated to burden of care and to depressive and anxious symptoms in caregivers. Also, there was a high correlation between burden of care and anxious symptoms in caregivers. We found statistically significant but not strong associations between depressive symptoms and depersonalization, depressive symptoms and personal accomplishment, and emotional exhaustion and patients' behavioral symptoms. There was also a statistical significant but weak association of caregiver age with time as caregiver, anxiety and depersonalization. Other weak associations were found between burden of care and depressive symptoms, and the former and depersonalization. Table IV further depicts the correlations of caregivers and patients variables with the burnout dimensions.

\section{Discussion}

The present study found that burden of care was the most significant factor associated to burnout in our sample. Additionally, emotional exhaustion was the most prevalent burnout dimension and was related to the cognitive, functional, and behavioral profile of patients and to the presence of depression, anxiety and burden of care in caregivers. The presence of emotional exhaustion associated to higher levels of cynicism in caregivers. Depersonalization was associated to patients' behavioral problems and to caregiver burden.

The observed prevalence of burnout was lower than the one found in the only

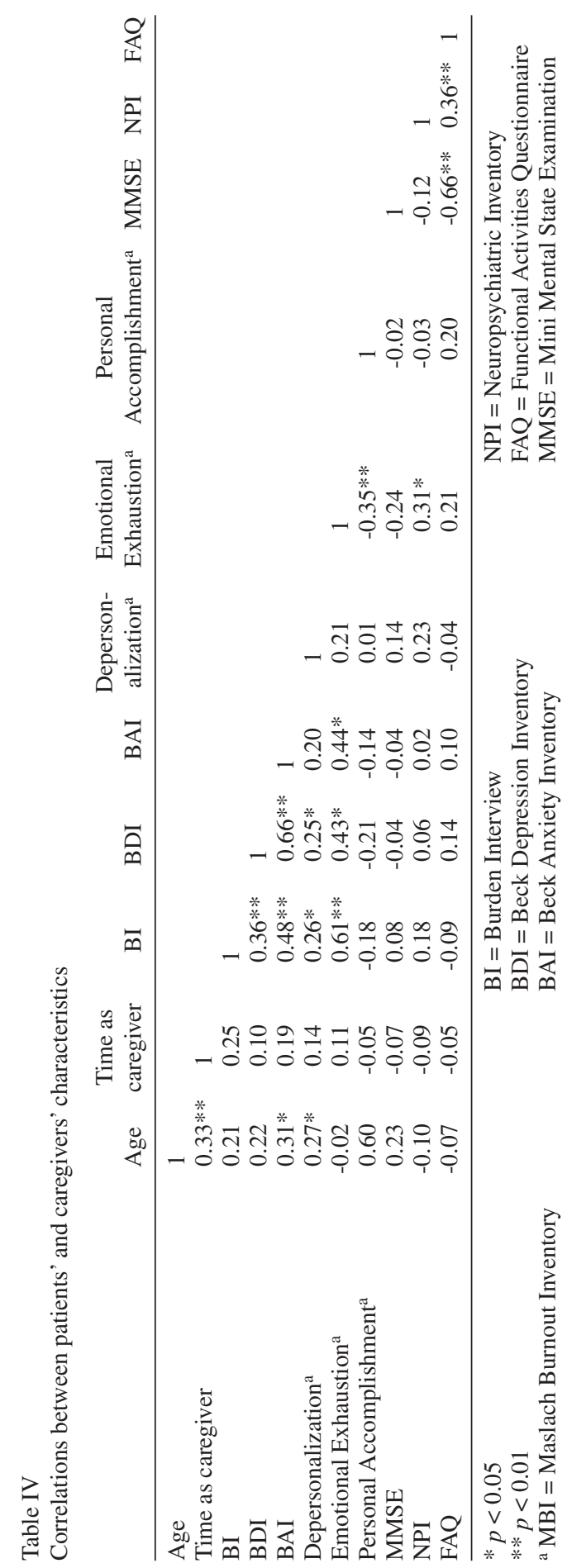


other study in the literature ${ }^{30}$ which yielded a prevalence of $17.4 \%$ in a community sample of informal caregivers of demented patients. As shown in our study, they also observed a strong association between subjective burden, particularly limitation in social life, and burnout. It ought to be mentioned, however, that some differences in the study design and in the samples preclude the comparison between the data drawn from the two studies.

Emotional exhaustion is the core burnout dimension and is directly associated to high levels of work overload ${ }^{31}$. Given that $\mathrm{AD}$ is a degenerative, progressive condition, it is reasonable to assume that this dimension is the most commonly reported by caregivers of patients who are more cognitively and functionally impaired, whose tasks turn out to be increasingly demanding. The fact that emotional exhaustion was associated to the patients' severity of neuropsychiatric symptoms in the present study supports the relationship between high levels of caregiver stress and patient's behavioral problems ${ }^{3}$. A wide body of literature states that caregivers of $\mathrm{AD}$ patients are at a higher risk for depression and anxiety ${ }^{32-34}$. Although our study does not allow to draw causal relationships because of its cross-sectional design, we found statistically significant although moderate correlations among depression and anxiety with emotional exhaustion. Further longitudinal studies will allow to infer whether burnout or any of its dimensions is indeed a risk factor for depression and anxiety in $\mathrm{AD}$ caregivers.

High demands in services and consequent work overload may compromise caregivers' ability to be involved with care recipients needs, leading to an indifferent attitude as an adaptive behavior that makes their demands more manageable and less burdensome ${ }^{8}$. Likewise, we found that caregivers with depersonalization showed higher levels of burden of care and emotional exhaustion. Moreover, high levels of cynicism in caregivers were also associated to the severity of behavioral symptoms in patients, meaning that they are a strong factor associated to the development of an indifference attitude from the caregivers towards $\mathrm{AD}$ patients.

Caregiver burden, particularly limitation in social life, has been associated to anxiety and depression in spouse caregivers ${ }^{35}$. Although our sample was more heterogeneous than the one in the mentioned study, we also found a significant correlation between high levels of burden of care and anxiety, indicating that the chronic stress involved in caregiving plays a major role to impair the wellbeing of caregivers.

A major limitation of our study is the small size of our sample. Moreover, the fact that our sample was drawn from a psychogeriatric reference center with a multidisciplinary staff and a variety of facilities including day hospital, social service, and familial group therapy may in part explain the small prevalence of burnout in our study.

To the best of our knowledge, this is the first study conducted in Brazil that examines burnout correlations to the clinical and sociodemographic factors of AD patients and their caregivers. Alzheimer's disease caregivers represent a vulnerable group to the effects of burnout since they are exposed to high levels of burden of care, only a few receive adequate training for this occupation, and the majority receive little positive feedback ${ }^{36}$. The assessment of burnout in caregivers permits not only the investigation of the emotional stress suffered by this group, as it has been largely described in the literature, but the interrelational aspects of caregiving and the caregiver's self-appraisal of care. This is an area that warrants more 
information that may lead to practical measures to deliver proper services both to patients and caregivers. To sum up, burnout associated to caregivers' burden of care. Among the burnout dimensions, emotional exhaustion was highly prevalent in our sample and also associated to the AD clinical status and to the burden of care, depression, and anxiety in caregivers.

\section{References}

1. Herrera E, Caramelli P, Silveira ASB, Nitrini R. Epidemiologic survey of dementia in a community-dwelling Brazilian population. Alzh Dis Assoc Disord 2002; 16: 103-108.

2. Nitrini R, Caramelli P, Herrera Jr E et al. Incidence of dementia in a community-dwelling Brazilian population. Alzh Dis Assoc Disord 2004; 18: 241-246.

3. Farcnik K, Persyko MS. Assessment, measures and approaches to easing caregiver burden in Alzheimer's disease. Drugs Aging 2002; 19(3): 203-215.

4. Mahoney R, Regan C, Katona C, Livingstone G. Anxiety and depression in family caregivers of people with Alzheimer's disease: The Laser-Ad Study. Am J Geriatr Psychiatry 2005; 13(9): 795-801.

5. Bandeira DR, Pawlowski J, Gonçalves TR, et al. Psychological distress in Brazilian caregivers of relatives with dementia. Aging Ment Health 2007; 11: 14-19.

6. Schultz R, O`Brien AT, Bookwala J, et al. Psychiatric and physical morbidity effects of dementia caregiving: prevalence correlates and causes. Gerontology 1995; 35: 771-791.

7. Sansoni J, Vellone E, Piras G. Anxiety and depression in community-dwelling, italian Alzheimer's disease caregivers. Int J Nurs Prac 2004; 10: 93-100.

8. Maslach C, Schaufeli WB, Leiter MP. Job burnout. Annu Rev Psychol 2001; 52: 397-422.

9. McKhann G, Drachman D, Folstein M, et al. Clinical diagnosis of Alzheimer's disease: report of the NINCDSADRDA Work Group under the auspices of department of health and human services task force on Alzheimer's disease. Neurology 1984; 939-944.

10. American Psychiatric Association. Diagnostic and Statistical Manual of Mental Disorders $4^{\text {th }}$ ed. Washington: American Psychiatric Press; 1994.
11. Feinberg LF, Pilisuk TL. Survey of fifteen states' caregivers support programs: final report. San Francisco: Familiy Caregiver Alliance; 1999.

12. Family Caregiver Alliance. Selected caregiver statistics: fact sheet. San Francisco: Family Caregiver Alliance; 1998.

13. Hughes CP, Berg L, Danziger WL, et al. A new clinical scale for the staging of dementia. Br J Psychiatry 1982; 140: 566-572.

14. Maia ALG, Godinho C, Ferreira ED, et al. Aplicação da versão brasileira da escala de avaliação clínica da demência (Clinical Dementia Rating - CDR) em amostras de pacientes com demência. Arq Neuropsiquiatr 2006; 64: 485-489.

15. Pfeffer RI, Kurosaki TT, Harrah CH, et al. Measurement of functional activities in older adults in the community. J Gerontol 1992; 37: 323-329.

16. Nitrini R, Caramelli P, Bottino CMC, et al. Diagnóstico de doença de Alzheimer no Brasil: avaliação cognitiva e funcional. Recomendações do Departamento Científico de Neurologia Cognitiva e do Envelhecimento da Academia Brasileira de Neurologia. Arq Neuropsiquiatr 2005; 63: 713-719.

17. Folstein MF, Folstein SE, McHugh PR. Mini Mental State: a practical method for grading the cognitive state of patients for the clinician. J Psychiatr Res 1975; 12: 189-198.

18. Bertolucci PHF, Brucki SMD, Campacci SR, Juliano Y. O mini exame do estado geral em uma população geral impacto da escolaridade. Arq Neuro-Psiquiatr 1994; 52:1-7.

19. Cummings JL, Mega M, Gray K, et al. The neuropsychiatric inventory: comprehensive assessment of psychopathology in dementia. Neurology 1994; 44: 23082314.

20. Camozzato AL, Kochhann R, Simeoni C, et al. Reliability of the Brazilian Portuguese version of the Neuropsychiatric Inventory (NPI) for patients with Alzheimer's disease and their caregivers. Int Psychogeriatr 2008; 20: 383-393.

21. Beck AT, Ward CH, Mendelson M, et al. An inventory for measuring depression. Arch Gen Psychiatry 1961; 4: 53-63.

22. Gorestein C, Andrade L. Validation of a Portuguese version of the Beck Depression Inventory and the StateTrait Anxiety Inventory in Brazilian subjects. Braz J Med Biol Res 1996; 29: 453-457.

23. Beck AT, Brown G, Epstein N, Steer RA. An inventory for measuring clinical anxiety. J Consult Clin Psychol 1988; 56: 893-897. 
24. Cunha JA. Manual das versões em português das escalas Beck. São Paulo: Casa do Psicólogo; 2001.

25. Maslach C, Jackson SE, Leiter MP. Maslach Burnout Inventory Manual. Palo Alto: Consulting Psychologist Press; 1996.

26. Benevides-Pereira AMT. Burnout: O processo de adoecer pelo trabalho. In: Benevides-Pereira AMT, ed. Burnout: Quando o trabalho ameaça o bem estar do trabalhador. São Paulo: Casa do Psicólogo 2002; 21-91.

27. McCallion P, McCarron M, Nickle T. Dementia and carer burnout: usefulness of the Maslach Burnout Inventory. J Appl Res Int Dis 2006; 19(3): 230.

28. Zarit SH, Reever KE, Bach-Peterson J. Relatives of the impaired elderly: correlates of feeling of burden. Gerontologist 1980; 20(6): 649-655.

29. Taub A, Andreoli SB, Bertolucci PH. Dementia caregiver burden: reliability of the Brazilian version of the Zarit caregiver burden interview. Cad Saude Publica 2004; 20: 372-376.

30. Almberg B, Grafstrom M, Winblad B. Caring for a demented elderly person - burden and burnout among caregiving relatives. J Adv Nurs 1997; 25(1): 109-116.

31. Felton JS. Burnout as a clinical entity - its importance in health care workers. Occup Med (Lond) 1998; 48(4): 237-250.
32. Parks SH, Pilisuk M. Caregivers' burden: gender and the psychological costs of caregiving. Am J Orthopsychiatry 1991; 61: 501-509.

33. Russo J, Vitaliano PP, Brewer DD, et al. Psychiatric disorders in spouse caregivers of care recipients with Alzheimer's disease and matched controls: a stress model of psychopathology. J Abnorm Psychol 1995; 104: 197-204.

34. Wright L, Hickey J, Buckwalter K, et al. Emotional and physical health of spouse caregivers of persons with Alzheimer's disease and stroke. J Adv Nurs 1999; 30: 552563.

35. Croog SH, Burleson JA, Sudilovsky A, Baume RM. Spouse caregivers of Alzheimer patients: problem responses to caregiver burden. Aging Ment Health 2006; 10: 87-100.

36. Hubbell L, Hubbell K. The burnout risk for male caregivers in providing care to spouses afflicted with Alzheimer's disease. J Health Hum Serv Adm 2002; 25: 115-132.

Address for correspondence:

Jerson Laks

Av Copacabana 749/802

22050-000 Rio de Janeiro, RJ, Brazil

Phone/Fax: +55 212255 3454/ +552125484510

E-mail: jlaks@centroin.com.br 